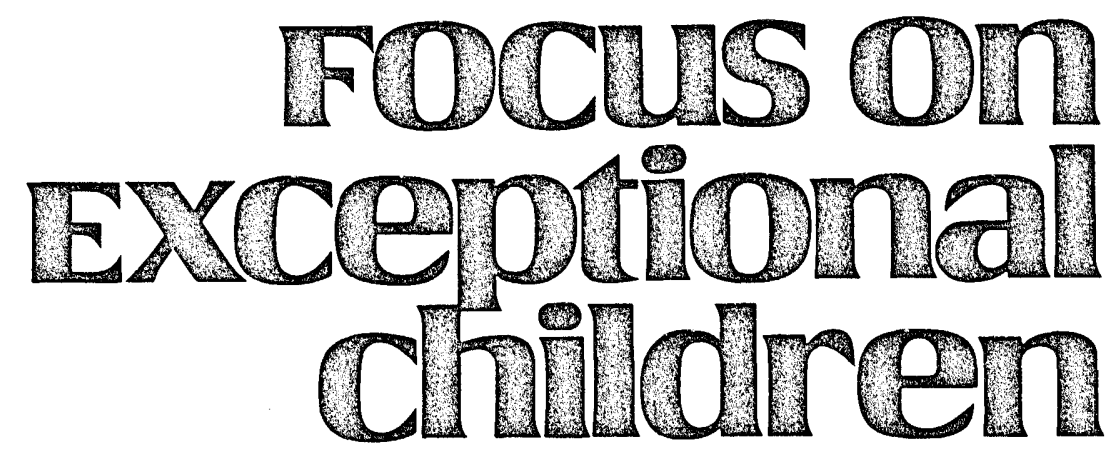

\title{
Transition from School to Adulthood For Youth with Severe Handicaps
}

\author{
Paul Wehman, M. Sherril Moon, and Pat McCarthy
}

Within the past decade thousands of children labeled severely handicapped have received special education services financed through public funds. As these children become young adults and leave school, the forms of adult vocational and residential services available to them take on a new interest and importance. Most of these individuals will require support or specialized help to function in the community. Students like Jack, Marianne, and Robin-who previously have been labeled as severely mentally retarded, autistic, and deaf-blind - will now for the first time be looking for job placement assistance, on-the-job training, travel training to be able to reach their jobs, aid in living in a supervised apartment or group home, and support for improving recreational options in the community. Unfortunately, community services such as these have lagged severely in the development of special education programs. Typically, adult vocational and residential services for persons with severe handicaps are in short supply with long waiting lists. This creates serious problems for students in need of transition assistance into adulthood and even has begun generating lawsuits for these services (Washington Post, June 28, 1985).

The dilemma that young people like Jack, Marianne, and Robin are experiencing is not unique. Will (1984) has estimated that well over 250,000 handicapped youths are exiting special education each year into adulthood; of this number, an estimated 10,00050,000 students probably could be considered severely handicapped, depending on which federal agency definition is used (see the later discussion on "Definitions of Severely Handicapped"). Elder (1984) has indicated that over $60 \%$ of all special education students in the United States are between 15 and 21 years of age. Many of these students require specialized services to attain meaningful employment and independent living competence. Hence, the topic of transition becomes critically important to Jack and his parents and the thousands of other families in similar situations.

Dr. Wehman is Director of the Rehabilitation Research and Training Center, Virginia Commonwealth University, with which co-authors Moon and McCarthy are also affiliated. 


\section{WHAT IS TRANSITION?}

Transition is a term that has been used frequently in professional circles (Brown et al., 1981; Rusch \& ChadseyRusch, 1985). The U.S. Department of Education, Office of Special Education and Rehabilitative Services (OSERS) has made transition a major priority. The Assistant Secretary of this office, Madeleine Will, and her staff developed a conceptual transition model (1984), which is characterized by an emphasis on quality secondary programs, a description of generic employment services, time-limited employment services, ongoing employment services, and an array of adult employment alternatives. Each of these three employment services is viewed as a "bridge" from school to work. Generic services are those already available to nonhandicapped people in the community (e.g., personnel agencies) and probably would be used by mildly handicapped consumers. Time-limited services, on the other hand, are specialized rehabilitative or other adult services that are uniquely suited to help a handicapped person gain employment; these services come to an end at some point once the individual is successful. Ongoing services (also called supported employment services) have not been available in most communities

\section{FOCus on Exceptional children}

FOCUS ON EXCEPTIONAL CHILDREN (ISS N0015-5IIX) (USPS 203-360) is published monthly except June, July, and August as a service to teachers, special educators, curriculum specialists, administrators, and those concerned with the special education of exceptional children. This journal is abstracted and indexed in Exceptional Child Education Resources, and is also available in microform from Xerox University Microfilm. Ann Arbor, Michigan. Subscription rates, $\$ 18.00$ per year. Copyright $\odot 1986$, Love Publishing Company. All rights reserved. Reproduction in whole or part without written permission is prohibited. Printed in the United States of America. Second class postage is paid at Denver, Colorado.

POSTMASTER: Send address changes to:

Love Publishing Company

Executive and Editorial Office

1777 South Bellaire Street

Denver, Colorado 80222

Telephone (303) 757-2579

EDITORIAL BOARD

Edward L. Meyen

University of Kansas

Richard J. Whelan

Glenn A. Vergason

Georgia State University

University of Kansas Medical Center
Stanley F. Love

Publisher
Carolyn Acheson

Senior Editor but would be aimed at hard-to-place severely handicapped people.

Wehman, Kregel, and Barcus (in press) have described vocational transition in the following definition:

\begin{abstract}
Vocational transition is a carefully planned process, which may be initiated either by school personnel or by adult service providers, to establish and implement a plan for either employment or additional vocational training of a handicapped student who will graduate or leave school in three to five years; such a process must involve special educators, vocational educators, parents and/or the student, an adult service system representative, and possibly an employer.
\end{abstract}

The key aspects of this definition are that (1) members of multiple disciplines and service delivery systems must participate, (2) parental involvement is essential, (3) vocational transition planning must occur well before 21 years of age, (4) the process must be planned and systematic, and (5) the vocational service must be of a quality nature. Transitioning a young woman with autism from a school program that provides instruction in learning letters of the alphabet, days of the week, seasons of the year, coloring, and other preschool developmental activities into a different setting (such as an adult activity center) with the same training objectives accomplishes little and distorts the purpose of the transition initiative.

Halpern (1985) broadened the OSERS emphasis from primary vocational to community adjustment. Community adjustment is seen as requiring competence in social and interpersonal skills, home living, and employment. Halpern believes that social and interpersonal skills may be the most important element of all in transition.

We believe that both employment and independent living are critically important aspects of the change from school to adulthood for all students, not only those with severe handicaps. Therefore, this article focuses not only on vocational alternatives after age 21 , but community living and recreational opportunities as well.

\section{FACTORS INFLUENCING TRANSITION DURING PAST DECADES}

Transition of youth from school to adulthood is a topic that is gaining much interest among professionals in special education, developmental disabilities, and rehabilitation. The expanding literature in this area involves descriptive case studies (Zetlin \& Turner, 1985), vocational transitional models (Wehman, Kregel, \& Barcus, 1985), and community integration transition models (Halpern, 1985), as well as process related articles (McCarthy, Everson, Inge, \& Barcus, 1985). A brief review of the major influences that seem to undergird the national movement in this area may be helpful. 


\section{Role of The Federal Government}

The weight of the federal government has been influential in several ways. The Education for Handicapped Children Amendments (PL 98-199) include a Secondary Education and Transition Services Section. Section 626 authorizes funds to be spent on research, training, and demonstration in the transition area. Another key aspect of involvement by the federal government has been the leadership of the U. S. Department of Education, Office of Special Education and Rehabilitative Services, under Assistant Secretary Madeleine Will and Commissioner Jean Elder of the Administration on Developmental Disabilities. The policies, orchestrated use of federal discretionary money, and far-reaching effects ( ocused communication by these two offices has had the d...natic effect of riveting the attention of service providers, educators, university personnel, and others on the subject of transition. Perhaps most significantly, large numbers of previously unserved or underserved handicapped children are beginning to near the end of their special education. These individuals want to know what is available for them after school. Many of the parents of these children are highly informed and not willing to settle for just any type of adult services. The advocacy role of these parents is placing enormous pressure on vocational rehabilitation and adult service agencies to expand present employment alternatives.

\section{Role of Vocational Training Technology}

In addition to the substantial role the federal government has played in promoting transition, a large amount of new information is becoming available on the demonstrated vocational competencies of persons with severe handicaps. The past 15 years have seen an explosion of articles in this area. These illustrations and descriptions of vocational, as well as independent living, competence by persons with severe handicaps has led to greater employment opportunities and improved expectations on the part of consumers, parents, and some professionals. The realization that many more persons with severe handicaps can perform real jobs has made transition a highly viable and meaningful topicone of serious urgency.

\section{Role of the Media}

A third factor that seems to be influencing the importance of the transition is the media. Both the electronic and print media demonstrate a growing interest and awareness that persons with severe handicaps can work and live in the community. Articles by Drogin (Los Angeles Times, March 17, 1985), McLeod (Psychology Today, March 1985), and
Klinger (Alexandria, Virginia Gazette, May 1985) are becoming increasingly common. As the media become more involved, skeptical professionals and uninformed parents, as well as the community at large, will begin to change or develop more responsive attitudes.

\section{DEFINTIONS OF SEVERELY HANDICAPPED}

Before going further, we should review what is meant by the label severely handicapped. It has many definitions and perceptions (Bellamy, 1985). For purposes of this article, the following definition of severely handicapped individuals, used by the U. S. Department of Education, Office of Special Education and Rehabilitative Services (OSERS), in the Education of the Handicapped Act regulations, will be utilized:

\footnotetext{
Severely handicapped refers to persons who, because of the intensity of their physical, mental or emotional problems, need highly specialized educational, social, psychological and medical services in order to maximize their full potential for useful and meaningful participation in society and for self-fulfillment. The term includes persons who are classified as seriously emotionally disturbed (including schizophrenic), autistic, profoundly and severely mentally retarded, and those with two or more serious handicapping conditions, such as the deaf-blind, mentally retarded-blind and the cerebral-palsied deaf.
}

Note that the government utilizes a variety of definitions for severely handicapped individuals. These definitions usually are related to eligibility requirements for particular services. For example, two other governmental entities charged with providing services to handicapped people are the Rehabilitation Services Administration (RSA), which provides for vocational rehabilitation services, and the Social Security Administration (SSA), which provides for disability benefits. RSA and SSA services (and definitions) relate specifically to an individual's employability, whereas the OSERS definition encompasses services necessary to maximize a person's potential, including employment. The Developmental Disabilities Act provides yet another definition by functionally identifying various life activities in which individuals must be deficient to be considered developmentally disabled.

\section{EMPLOYMENT ALTERNATIVES FOR PERSONS WITH SEVERE HANDICAPS}

Within the past 15 years the number of adult day programs and sheltered workshops for persons with disabilities has dramatically increased. For example, approximately 2,000 adult activity centers alone exist today, as compared to under 200 in the early 1970s (Bellamy et al., 1980). Few communities in this country do not have some form of adult day service for persons with disabilities. These programs typi- 
cally are funded by social service or mental health/mental retardation monies or, in the case of sheltered workshops, principally with rehabilitation dollars. The adult day program service model emphasizes the concept of readinessthe need for individuals to develop skills and overcome disabilities so they can enter vocational rehabilitation or competitive employment at some future time.

In theory, the notion of movement through a prescribed developmental continuum of adult activity, sheltered work, sheltered enclave, competitive employment, and so on may seem appealing, but in reality it does not work. Especially for persons with severe handicaps, little or no movement occurs and placement in segregated day programs becomes terminal. What makes this practice particularly disturbing is that research and demonstration have shown that many more persons with moderate and severe handicaps could work if they were given an opportunity and support. Specialized assistance and adaptation of skills necessary for success can make the difference for many persons. We will review several of the types of adult service alternatives now available to special education students with severe handicaps, beginning with the least desirable of these alternatives.

\section{Adult Activity Centers and Sheltered Workshops}

In most cities and towns young adults with severe handicaps go to special centers after they finish school. Many go to places that are variously called adult activity centers, developmental achievement centers, stimulation centers, and the like. These day programs have grown enormously in number, with approximately 2,000 in the country. Many other young adults are accepted in work activity or sheltered workshop programs. Sheltered workshops number well over 5,000 . Many more young adults are at home because of an unavailability of services.

Within day programs participants receive the opportunity to recreate, learn activities of daily living, learn academics, and be involved in some work skill activity. Sheltered workshops, on the other hand, provide for contract bench work under sheltered conditions, and only with other mentally or physically disabled peers. Sheltered workshop employees typically earn an average of $\$ 1$ to $\$ 3$ per day. Most parents and young people with severe handicaps, as well as professionals, have come to expect this form of service. With increasing numbers of students leaving school and needing adult service, a move has been made by some to further expand segregated adult day programs. In most states adult activity centers cost annually anywhere from $\$ 4,200$ per client (Virginia) to $\$ 7,500$ per client (Maryland). Sheltered workshops usually cost more in the range of $\$ 2,500-\$ 3,000$ annually per client.

The special day program that takes place in a segregated center must come to an end. This arrangement places too many fiscal resources into buildings, not staff. A more significant disadvantage results from the segregation of people with severe handicaps away from the community. Furthermore, the emphasis of these programs is not on finding employment with decent pay in the community-in spite of the many successful programs demonstrated through research. The underlying assumption has been that clients are not "ready" and need much more training.

Though the tendency has been for professionals and parents to think that the best way to provide adult services is in a special building, some alternative approaches fortunately are becoming available.

\section{Supported Employment}

The preceding discussion points up the reality that many severely handicapped persons will never gain entrance to employment in industry under the current service delivery system. Also, many significantly impaired persons will never earn money at a real job in the community without professional support. Hence, the concept of supported employment has evolved within recent years as an alternative for severely disabled persons. Supported employment provides opportunities to work for the first time for many people who are at substantial risk of gaining and maintaining employment. It may invoive a host of different arrangements within industry or outside of industry, in different occupations, and with different staffing patterns. Supported employment, however, has four consistent characteristics or: themes: (1) paid employment, (2) integration into the community, (3) neccessity for ongoing support, and (4) the presence of severe disability. Supported employment is not for all handicapped youth transitioning into adulthood but would be for most students with severe handicaps.

\section{Paid Employment}

Supported employment is paid employment that cannot exist without a regular opportunity to work. The federal government has suggested that an individual should be considered to meet the paid employment aspect of supported employment if he or she engages in paid work for at least an average of 4 hours each day, 5 days per week, or another schedule offering at least 20 hours of work per week. This standard does not establish a minimum wage or productivity level for supported employment.

The amount of hours worked should not be viewed as the only criterion for supported employment, because some people (such as severely handicapped teenagers) may choose to work only 15 hours a week. The stipulation of number of hours worked, however, does convey the seriousness and impact that paid employment may have on the disabled young person. 


\section{Community Integration}

Work is integrated when it provides frequent daily social interactions with people without disabilities who are not paid caregivers. The federal government has suggested that integration in supported employment programs be defined in terms of a place where (1) no more than eight people with disabilities work together and is not immediately adjacent to another program serving persons with disabilities, and (2) persons without disabilities who are not paid caregivers are present in the work setting or immediate vicinity.

For example, an individual with severe cerebral palsy who works in a local bank creating microfilm records of transactions clearly meets the integration criteria for supported employment. So do: four individuals with severe emotional disorders who work together in an enclave within a manufacturing plant; a mobile janitorial crew that employs five persons with moderate mental retardation in community work sites; and a small bakery that employs persons with and without disabilities.

\section{Ongoing Support}

Supported employment exists only when ongoing support is provided. An individual should be considered to be receiving ongoing support when public funds are available on an ongoing basis to an individual or service provider who is responsible for providing employment support and when these funds are used for specialized assistance directly related to sustaining employment.

The nature of ongoing support-which is ongoing through the entire span of the individual's employment-differs markedly from the time-limited nature of traditional rehabilitation services. This characteristic is truly unique and positively influences the concerns of parents and employers.

\section{Severe Disability}

Supported employment exists when the persons served require ongoing support; it is inappropriate for persons who would be better served in time-limited preparation programs leading to independent employment. The most significant way to describe who should receive supported employment is to assess how much an individual is at risk of gaining and maintaining employment. Youths who are highly likely to lose jobs shortly after placement because of their disability may be prime candidates for supported employment. This means that individuals labled autistic, trainable, severely or profoundly mentally retarded, and multiply handicapped would be the principal target groups for this approach. These individuals would not be able to hold jobs without permanent, long-term, follow-along at the job site.

\section{Supported Competitive Employment}

Competitive employment also should be made available to severely handicapped individuals who need help getting a job, learning and adjusting to a job, and holding a job (Revell, Wehman, \& Arnold, 1984; Wehman, 1981; Wehman \& Kregel, 1985). Many persons with mild, moderate, and severe mental handicaps, autism, behavior disorders, or multiple handicaps have not fared well in competitive employment. Generally, they have difficulties in learning and performing the job, greater parental concerns, transportation problems, and also fears of losing social security payments. Yet, fortunately programs and efforts are under way that demonstrate how supported work with the aid of an ongoing job coordinator can help this historically unemployed population gain entry into the labor force (Brickey \& Campbell, 1981; Rusch \& Mithaug, 1980; O'Neill \& Associates, Washington Developmental Disabilities, 1984; Wehman et al., 1982).

A supported work approach to competitive employment emphasizes structured assistance in job placement and job site training. A job coach is readily accessible for individualized one-to-one training and follow-up (Wehman \& Melia, 1985). A strong focus of this model is on helping individuals maintain their jobs. At first glance it might appear too expensive, but in fact a significant cost savings is derived, comparatively, because of the amount of money required to rehabilitate this population, as well as a reduction in the social security transfer payments (Hill \& Wehman, 1983).

\section{Enclaves in Industry}

Another possible vocational outcome for more substantially disabled persons is the sheltered enclave (Rhodes \& Valenta, 1985). With this approach small groups of disabled individuals (fewer than six) are employed in business and industry under the daily supervision of a trained human service staff person. The enclave is attractive because it offers disabled clients who traditionally have been excluded from employment services the opportunity to work in a natural work environment such as business or industry, usually for a decent wage. The hours and working conditions may be more limited and unlike either of the previously mentioned alternatives. Fringe benefits usually are not an option. In addition, although breaks and lunch provide for integration with nonhandicapped co-workers, most enclaves place disabled workers together on a special set of tasks. The sheltered enclave may be a good opportunity for some severely disabled workers to eventually move into part- or even full-time competitive employment. 


\section{Mobile Work Crews}

Similar to sheltered enclaves, mobile work crews have a permanent supervisor with a small group of disabled workers. An obvious difference, however, is that work is performed at different locations of a building or community. The workers do not remain stationary. Examples of mobile work crews would be yard maintenance crews, paint crews, and janitorial cleaning. With both enclaves and work crews, work contracts usually are made available to the agency or sponsoring nonprofit corporation. The funds from these con- , tracts serve as the source of funds to pay the disabled workers and subsidize the staff support.

Mobile work crews and enclaves are attractive forms of providing wages and an integrated work setting for persons who may require substantial supervision and structure. Examples and illustrations of how this work arrangement can operate with persons labeled severely and profoundly retarded are few, but the behavioral training technology that has made other vocational training efforts successful (e.g., Bellamy, Horner, \& Inman, 1979) clearly can be applied within these arrangements. Hundreds of people labeled severely handicapped should be able to vocationally function in a work situation similar to one of the three suggested models described here, and many more creative models can be established by enterprising entrepreneurs.

\section{Major Outcomes Associated With Supported Employment}

The various positive outcomes associated with working in industry are numerous. Readers interested in in-depth discussions of this topic are referred to Hill, Hill, Wehman, and Banks (1985), Hill and Wehman (1983), Rusch (in press), and Wehman (1981).

\section{SUCCESSFUL COMMUNITY LIVING}

As important as vocational outcomes are for students with severe handicaps, so, too, are independent living skills. Residential support services are crucial for helping young severely handicapped adults adjust to independent living. All citizens, including those who are disabled, should be entitled to a home that is the "least restrictive." Unfortunately, hardly any community has a full range of residential services to meet the needs of each individual citizen. One of the major challenges facing every community today is to facilitate the integration of handicapped persons into appropriate residential alternatives (Pancsofar, 1985; Sheerenberger, 1974). In fact, living successfully in one's community, rather than obtaining employment, should be the main target of transitional services, according to Halpern (1985). We believe that transition planning must include goals and objectives for movement into employment, appropriate adult residential settings, and age-appropriate leisure activities.

\section{Residential Alternatives}

Some students who are severely handicapped may have the potential and the resources to do well in independent living arrangements in which they are not reliant on support services other than those available to all citizens. An arrangement of this type may be a single-family home, a home shared with another handicapped person, an unsupervised apartment, or a residential hotel (Pancsofar, 1985; Thompson, 1977). Most severely disabled persons, however, need some type of supervision that can be provided in a number of ways.

Heal, Novak, Sigelman, and Switsky (1980) delineated several supported community living options in a continuum ranging from least to most restrictive. These included, among others, natural homes, living with relatives, foster homes, group homes, nursing homes, hotels, sheltered villages, and at the bottom of the continuum, public and private residential facilities. Of course, a number of factors must be weighed in determining what is the most appropriate living arrangement for any individual. Pancsofar (1985) listed five: (1) availability within a community, (2) preferences of an individual, (3) age of an individual, (4) closeness to work, recreation, and friends, and (5) receptivity of neighbors.

Another means that Pancsofar discussed for determining the most appropriate living setting deals with establishing a level of assistance that a person needs to function in the community. Thus, the type of building becomes less critical than the type and amount of professional and paraprofessional staff assigned to that person. Baker, Seltzer, and Seltzer (1977) found that community residences such as small group homes, apartments, and homes for the elderly were more "normalizing" than large group homes, foster homes, and work placement residences (room and board provided as a condition of employment).

Hill, Lakin, and Bruininks (1984) reported on a classification system for community-based supported residential options in which citizens with severe handicaps are now living. We believe that, optimally, every locality or district, depending on the service provision system of the state, should have several of these options. First, persons with severe handicaps should be able to remain with their natural families when the situation is favorable for the entire family. Although this is somewhat age-inappropriate for an adult, it typically is the most cost-effective placement (Willer, Intagliata, \& Wicks, 1981). To make this option more viable, families must receive more financial assistance, in-home training in matters such as acute behavioral disruptions, and 
a systematic network of long- and short-term respite care.

Family care homes or foster homes in which the residence is owned or rented by a family member and the person with the severe disability lives as a family member is the second option. The critical factor in facilitating these residential options is to make sure that the primary caregivers in the family are properly trained and supported with an array of financial and human services. Research also indicates that caregiver preferences for the type of disability of the potential new family member must be matched closely with the characteristics and needs of the disabled individual (Lei, Nihira, Sheehy, \& Meyers, 1981). Finally, the agencies responsible for finding and maintaining family care homes must establish criteria based on the principles of normalization and least restrictive living by which to monitor the appropriateness of these placements.

The third category consists of group residences in which a professional staff provides supervision and training to a group of disabled persons. Group homes typify this type of community-based residence. The residence might be small and much like a family residence, or it may be large and similar in appearance to an institution. Smaller group homes generally are more desirable, and the number of residents should approximate the size of a family, which usually is between three and eight. These homes should be located in nice residential neighborhoods, accessible to community employment, recreational and shopping facilities. Because group homes traditionally have round-the-clock professional staff members on duty, they should provide training that allows the residents to move eventually to a less restrictive home, such as a supervised apartment complex. Although group homes have housed more severely handicapped individuals than any community-based option other than nursing homes, they should not be viewed as the best alternative to large residential facilities (the least attractive alternative).

The fourth possibility for community-based living is a semi-independent facility consisting of self-contained units for both staff and disabled residents. Supervised apartment complexes or units within a complex are examples. This option generally calls for round-the-clock availability of supervision, and some facilities provide formal, regular training programs. As with group homes, these residences should be in nice neighborhoods and accessible to shopping, recreation, and employment.

Other community-based options-which are less desirable, in our opinion-include boarding homes, personal care homes, and nursing homes. These residences often are isolated from the day-to-day activities of a community, and residents typically are older or more medically disabled than school-aged citizens with severe disabilities. Also, the amount of supervision provided in these residences may be informal and sporadic. Since each place is different, however, all should be evaluated as a possibility, depending on the needs of the individual.

\section{Community Support Services}

Simply moving a person with severe disabilities into what appears to be the most appropriate residential setting does not ensure successful, integrated living in one's community. A whole array of generic services, including legal, medical, financial, recreation, and employment, must be provided (Savage, Novak, \& Heal, 1980). In fact, the presence of a wide array of services correlates directly to the community adjustment of persons formerly institutionalized, regardless of their residential placement.

One major support service that often has been overlooked is the availability of social contacts to adults with disabilities. One solution is the provision of a volunteer or paid advocate acting on a regular basis as a friend rather than as a trainer or supervisor. This person could make sure that the disabled individual becomes involved in recreational, religious, cultural, and political events by participating with him or her. Another service that often is inadequate is transportationparticularly in rural communities. This factor alone has prevented many persons who are otherwise capable from obtaining jobs in community-based settings (Wehman, 1981).

Some experts have suggested that community support services to citizens with severe handicaps would improve if we were to become less dependent on specialized programs (Scheerenberger, 1976). All service providers should be trained to deal with developmentally disabled persons. Specialists could float among agencies to provide expertise to other professionals, and a coordinating body could help in referring and dispensing services.

\section{DEVELOPING A CURRICULUM TO ENHANCE TRANSITION}

If students are going to be transitioned into appropriate employment and independent living situations, a method of longitudinal instruction (described later), based on functional activities required to live and work in a particular community, must be established. Most experts in the area of education of persons who are severely handicapped agree that a curriculum should be developed according to the following tenets (Bates, 1985; Brown, Branston-McClean, Baumgart, Vincent, Falvey, \& Schroeder, 1979; Wehman, Renzaglia, \& Bates, 1985; Wilcox \& Bellamy, 1982).

First, a curriculum must be locally referenced so that it reflects vocational, recreational, and independent living skills needed to function in a particular community. Second, because the curriculum is based on teaching functional activities, instruction must be done in community-based settings rather than in a traditional classroom setting. And students must be trained across the array of possible future living and work options so that the most appropriate options can be targeted by graduation time. Third, curriculum de- 
velopment must be viewed as a longitudinal or ongoing process that is begun very early and is continually added to or modified as a student gains functional competencies.

What exactly is taught to each student will depend on current and impending community options available to him or her as an adult. To identify these options, the educator must continually assess the local resources. Brown, Nietupski, and Hamre-Nietupski (1976) described a method of curriculum development for students who were severely handicapped that moved away from a traditional developmental approach that had emphasized training isolated motor, pre-cognitive, and simple self-care skills. The new curriculum development model was based on looking at environments in which a nonhandicapped adult must survive, and then teaching behaviors necessary to function in these environments.

The major curriculum areas, based on this model, shift to more functional categories including vocational, home/ community (sometimes grouped together as independent living), and leisure. These domains, as they are most commonly referred to in the literature, then are further analyzed to pinpoint specific environments in which someone must function on a day-to-day basis. Once environments are identified, activities can be identified and prioritized for instruction. This process has been referred to by some as "conducting an ecological analysis" (Wehman, Renzaglia, \& Bates, 1984), or simply as "cataloging local opportunities" (Wilcox \& Bellamy, 1982).

This process allows educators, parents, and adult service providers to jointly pinpoint current and future work, recreational and living options for each student, and then to start training at an early age. It also gives instructors the opportunity to teach several activities within the context of the adult situation in which behaviors are ultimately expected to occur. For example, perhaps a supervised apartment program has been identified as a possible independent living situation for several students in a class. In that case, the activities to be taught may include participating in specific leisure activities, using a city bus, using particular kitchen appliances, doing yard work, washing and drying clothes at a nearby laundry, and getting up independently at a certain time. The only way to assure that the student is transitioned into that particular apartment program is to prove that he or she can perform the activities that are required to live there.

In terms of vocational environments, the best way to identify local options is to start with general screening techniques such as reading newspaper classified ads, checking with local employment agencies, calling the Chamber of Commerce, and talking with rehabilitation professionals who have done successful job placement (Wehman \& Moon, 1985). Further contact by phone or in person will give an even better idea of types of job skills required for a particular position. Of course, local sheltered workshop and adult ac- tivity programs also should be analyzed closely and then incorporated into training objectives as a last resort for the most handicapped students. Even a less than desirable option is better than no option at all after school graduation.

\section{INDIVIDUALIZED TRANSITION PLAN}

As the individualized education plan (IEP) became the catalyst to appropriate instruction for students with severe handicaps in areas such as self-help skills, the individualized transition plan (ITP) is the key to successful transition of the student into work and community living options by the time he or she leaves school. Although the ITP may be a part of the IEP, it must be addressed separately, with a focus on the student's independent adult life. By the time a student reaches age 16, the first ITP should be developed. Generally, the special education teacher or other designated school employee (e.g., counselor, social worker, psychologist, transition coordinator) takes the lead in contacting appropriate representatives for a planning team to attend transition meetings. Composition of the team depends on the unique needs of the student. An important element in team member selection is the joint involvement of school personnel responsible for training and job procurement, as well as human service providers who could offer support and follow-up during the student's adulthood.

Composition of the vocational portion of the ITP, when the student is age 16, entails long-range goals related to the supported work model that would be appropriate to him or her, such as enclaves, supported competitive employment, or work crews. Independent living goals are based on the community similar to that in which the individual will be integrated as an adult. The plan is further broken down into objectives that should lead to community living goals and employment goals. These objectives incorporate two major categories: educational and administrative. For each objective, a specific person representing an agency will be identified as the party responsible for accomplishment of the objective. Each objective also will delineate a projected completion date. Figure 1 illustrates a sample ITP written for Bob, a 16-year-old student who is moderately mentally retarded with severe autistic characteristics.

\section{Educational Objectives}

The objectives relating to employment address exposure of the student to a variety of jobs during the high school years, to prepare him or her for the targeted work options. Experience in a variety of jobs is essential for students with severe disabilities so that when job placement occurs, they will have concrete experiences to help them communicate a sound, educated opinion on their career selection. Objec- 
tives to accomplish the community living goal should involve training in a home and in a general community setting. If longitudinal functional skill training has occurred, the 16year-old student may have many domestic, community, and leisure skills such as housekeeping, shopping, or lawn care. The issue then becomes teaching the student to self-initiate activities and to respond appropriately in unusual and emergency situations.

\section{Administrative Objectives}

A major administrative objective might entail conducting a needs assessment of the community to determine what is currently available and what has to be developed before the student reaches school-leaving age 2-3 years later. Assignments for this objective could possibly be the special education consultant, the Child Study Team coordinator, or an assistant administrator in the school. Leading from this objective would be the development of a specific employment or residential option or component thereof.

For example, if the student is targeted for supportive competitive employment and the special education teacher places him or her into a job prior to leaving school, the student will need follow-along during adulthood. If provisions for the follow-along component of supported competitive employment is not currently available in the community, an administrative objective to redistribute current funds to provide that service could be assigned to the case manager. Other administrative objectives might include accessing job training sites, procuring transportation, and establishing insurance coverage for students and teachers during non-paid job training.

\section{Review and Update}

Each year this ITP is reviewed and updated during the student's IEP meeting. Then, when the student reaches the time for job placement between the ages of 18 and 21, a new ITP should be written. The same major components will be delineated, but emphasis should be placed on identifying the person responsible for job placement and training, as well as follow-along services. A specific residential option also should be identified in this ITP, with the steps outlined for admission into the home or apartment. At this point in the student's development, adult service providers begin taking a much more active role in the process.

\section{Staff Training}

With a focus on employment and community living for persons who traditionally have not been fully integrated into the community, human service providers are faced with an evolution of role changes. Some of the more traditional responsibilities that encompass the majority of the service provider's job description may no longer be necessary. At the same time, the providers will have to adapt to new assignments. For example, the traditional special educator in a high school may spend the entire day in a classroom teaching work adjustment and independent living skills through films, worksheets, and role playing. With a community-based job training program, that same teacher is now called upon to procure job sites, conduct teaching in actual business settings, and provide training on city buses.

\section{PARENT EDUCATION AND INVOLVEMENT}

As schools embark on adopting a longitudinal vocational training program that leads to employment of persons with severe disabilities, they must prepare parents for a new perspective on the outcome of their offspring. Research indicates that the major predictor of success in job retention of persons with severe handicaps is parent support (Hill, Wehman, Hill, \& Goodall, 1985). To offer support, however, parents must be aware of the issues. As when PL 94-142 regulations were becoming a reality, parents should be educated in the components of quality vocational training, the array of employment options that should be, or already may be, available in the community, agency responsibilities in job training/placement, and the changing role of their disabled offspring in society. Programs such as Next Steps, a federally funded project designed to inform parents about employment issues, should become a part of the community service (Anderson, Beckett, Chitwood, \& Hayden, 1985).

\section{PUBLIC AWARENESS}

DeLoach, Wilkins, and Walker (1983) have explained that prior to adopting a theory, it must pass through the stages of conceptualization, initial acceptance, legislative legitimization and resource (re)allocation before full integration into the system. Currently, the idea of supported employment and community living options for persons with severe disabilities is in the stage of legislative legitimization and resource allocation. For progression beyond this point, communities must actively pursue a public awareness program.

Transformation of ideas does not occur merely through modeling. Throughout the country several projects have demonstrated the success of community integration of persons with severe disabilities (Paine, Bellamy, \& Wilcox, 1984; Kusserow, 1984; Wehman et al. in press). Yet agencies continue to pour funds into service programs versus employment outcomes, segregated work and domestic environments versus integrated environments and substandard or no wages versus minimum wages and benefits. An assertive effort must be made to educate the entrepreneur, the taxpayer, the potential worker with disabilities, human service agencies, and parents of what could and can be the adult life style for individuals with severe disabilities. 


\section{FIGURE 1 \\ INDIVIDUALIZED TRANSITION PLAN}

Name: Bob

Age: 16

Date: April 20, 1985

\section{A. Employment Goal:}

To become employed in an enclave by May, 1990 (age 20).

Educational Objectives:

1. To receive training in a production job enclave within a local industry with minimal supervision on a daily basis by December, 1985.

\section{Activities}

-Locate a job site

-Provide job site training

-Provide transportation training

-Assess skills as part of vocational assessment

-Develop behavioral interventions as necessary
Person(s) Responsible

Voc. Ed. teacher, Rehab. counselor

Sp. Ed teacher, Voc. Ed. teacher

Sp. Ed. teacher

Voc. Ed. teacher, Sp. Ed. teacher

School psychologist, Sp. Ed. teacher

2. To receive training in a food service enclave with minimal supervision on a daily basis by May, 1985 .

\section{Activities}

Same as \#1
Person(s) Responsible

Same as \#1

3. To receive training in a technological job such as micrographics or data entry with minimal supervision on a daily basis by December, 1986.
Activities
Same as \#1
Person(s) Responsible
Same as \#1

4. To receive training in a janitorial and/or grounds maintenance enclave for an office building with minimal supervision by a job coach by May, 1986.
Activities
Same as \#1
Person(s) Responsible
Same as \#1

5. To receive a completed vocational assessment and job identification based on skills and interests by September, 1986.
Activities
Person(s) Responsible

-Collect and analyze vocational assessment data during job training

-Determine appropriate job for Bob based on skills and interests demonstrated through job site training

Voc. Ed. teacher, Sp. Ed. teacher, Rehab. counselor

All ITP team members

6. To receive intensive job site training within the enclave type identified in \#5 by December, 1988.
Activities
Same as \#1
Person(s) Responsible
Same as \#1

Administrative Objectives:

1. To assure the development of a nonprofit organization receiving state, federal, and/or local funds to provide enclave supervision by May, 1989.
Activities
Person(s) Responsible

-Meet with community service boards and local rehabilitation agency to discuss the need for enclaves

- Lobby for funds to be allocated for an enclave

Sp. Ed. coordinator

Parent

2. To develop personnel policies to accommodate job site trainers by September, 1985.

Activities

-Develop overtime pay or compensation

-Develop policy to allow teachers to have flexible hours based on enclave hours
Person(s) Responsible

School superintendent

School superintendent 


\section{B. Community Living Goal:}

To move into a semi-independent apartment with not more than two other residents with disabilities and one staff resident by May, 1990.

\section{Educational Objectives:}

1. To perform the following domestic tasks with periodic checks by staff: housecleaning, grocery shopping, clothing list development, meal preparation, grooming, yard maintenance, and make necessary phone calls (doctor, MH/MR case manager, family) by May, 1989.
Activities
Person(s) Responsible
-Train skills in home
Sp. Ed. teacher
- Locate apartment for training
MH/MR case manager

-Develop necessary adaptations

Sp. Ed. teacher, O.T., Speech therapist

2. To initiate the performance of all routine home activities through use of a picture schedule for each day by May, 1989.

Activities
-Train independence in following sequence of
tasks

Person(s) Responsible

Sp. Ed. teacher

-Develop daily schedules

Sp. Ed. teacher

3. To respond to unusual situations in the manner outlined in the safety manual with no assistance from staff by May, 1989.

\section{Activities}

- Identify situations to be dealt with

-Develop safety procedures manual

-Train skills to deal with situations
Person(s) Responsible

$\mathrm{MH} / \mathrm{MR}$ case manager, apartment staff member

Sp. Ed. teacher, apartment staff member

Sp. Ed. teacher

4. To use the city bus with another student to go to the shopping mall, park, and medical clinic by May, 1988.

\section{Activities}

-Transportation training
Person(s) Responsible

Sp. Ed teacher

5. To locate appropriate store and shop for groceries or supplies with another student by May, 1988.

\section{Activities}

- Set up checking account

-Locate appropriate mall

-Train community skills
Person(s) Responsible

Parent, Bob

Sp. Ed. teacher

Sp. Ed. teacher, Parent

6. To inititate and independently perform at least one leisure skill in each of the following areas by May, 1989: solo activity such as needlework, solo outdoor activity such as bike riding; outdoor activity with another person such as frisbee, and a community activity such as skating.

\section{Activities}

- Select activity in each category

-Train leisure skills
Person(s) Responsible

Bob

Sp. Ed. teacher

Administrative Objectives:

1. To complete referral process to appropriate adult services by May, 1986.

\section{Activities}

-Make referral to VR

-Make referral for SSI and Medicaid
Person(s) Responsible

Rehab. counselor

Sp. Ed. coordinator

2. To obtain insurance coverage for students and staff during training in the apartment by September, 1985.

\section{Activities}

-Obtain insurance coverage
Person(s) Responsible

School superintendent

3. To assure the availability of semi-independent homes in the community to accommodate students leaving schools by May, 1987.

\section{Activities}

-Meet with local agency officials
Person(s) Responsible

Sp. Ed coordinator 


\section{REFERENCES}

Anderson, W., Beckett, C., Chitwood, S., \& Hayden, D. (1985). Next Steps: Planning for employment. Alexandria, VA: Parent Educational Advocacy Training Center.

Baker, F., Seltzer, G., \& Seltzer, M. (1977). As close as possible. Boston: Little, Brown.

Bates, P. (1985). Vocational curriculum development for students who are mentally retarded. In S. Moon, P. Wehman, \& P. Goodall (Eds.), Proceedings of the first RRTC symposium on supported employment for citizens who are mentally retarded. Richmond: Virginia Commonwealth University.

Bellamy, G. T., Horner, R., \& Inman, D. (1979). Vocational training of severely retarded adults. Baltimore: University Park Press.

Brickey, M., \& Campbell, K. (1981). Fast food employment for moderately and mildly retarded adults. The McDonald's project. Mental Retardation, 19, 113-116.

Brown, L., Branston-McClean, M. B., Baumgart, D., Vincent, L., Falvey, M., \& Schroeder, J. (1979). Using the characteristics of current and subsequent least restrictive environments in the development of curricular content for severely handicapped students. AAESPH Review, 4 (4), 407-424.

Brown, L., Nietupski, J., \& Hamre-Nietupski, S. (1976). Criterion of ultimate functioning. In M. Thomas (Ed.), Hey, don't forget about $m e$. Reston, VA: Council for Exceptional Children.

Brown, L., Pumpian, I., Baumgart, D., VanDeventer, L., Ford, A., Nisbet, J., Schneider, J., \& Gruenwald, L. (1981). Longitudinal transition plans in programs for severely handicapped students. Exceptional Children, 47 (8).

DeLoach, C., Wilkins, R., \& Walker, G. (1983). Independent living: Philosophy, process and services. Baltimore: University Park Press.

Drogin, R. (1985, March 16). Success in workplace. Los Angeles Times.

Elder, J. (1984). Job opportunities for developmentally disabled people. American Rehabilitation, 10(2), 26-30.

Halpern, A. S. (1985). Transition: A look at the foundations. Exceptional Children, 51 (6), 479-486.

Heal, L. W., Novak, A. R. Sigelman, C. K., \& Switsky, H. N. (1980). Characteristics of community residential facilities. In A. R. Novak \& L. W. Heal (Eds.), Integration of developmentally disabled individuals into the community (pp. 45-56). Baltimore: Paul H. Brookes.

Hill, B. K., Lakin, C., \& Bruininks, R. H. (1984). Trends in residential services for people who are mentally retarded: 1977-1982. Journal of the Association for the Severely Handicapped, 9(4), 243-250.

Hill, J., Wehman, P., Hill, M., \& Goodall, P. (1985). Differential reasons for job separation of previously employed mentally retarded persons across measured intelligence levels. In P. Wehman \& J. Hill (Eds.), Competitive employment for persons with mental retardation: From research to practice. Richmond: Virginia Commonwealth University, Rehabilitation Research \& Training Center.

Hill, M., Hill, J., Wehman, P., \& Banks, D. (1985). An analysis of monetary and nonmonetary outcomes associated with competitive employment of mentally retarded persons. In P. Wehman \& J. Hill (Eds.), Competitive employment for persons with mental retardation. Richmond: Virginia Commonwealth University, Rehabilitation Research \& Training Center.

Hill, M., \& Wehman, P. (1983). Costs benefit analysis of placing moderately and severely handicapped individuals into competitive employment. Journal of the Association for the Severely Handicapped, 8 , 30-38.

Klinger, R. (1985, May). Disabled youth at work. Alexandria (Virginia) Gazette.

Kusserow, R. (1984). A program inspection on transition of developmentally disabled young adults from school to adult services. Washington, DC: Dept. of Health \& Human Services.

Lei, T., Nihira, L., Sheehy, N., \& Meyers, C.E. (1981). A study of small family care for mentally retarded people. In R. H. Bruininks, C. E. Meyers, B. B. Sigford, \& K. C. Lakin (Eds.), Deinstitutionalization and community adjustment of mentally retarded people (pp. 265-281). Washington, DC: American Association on Mental Deficiency.

McCarthy, P., Everson, J., Inge, K., \& Barcus, M. (1985). Transition from school to work: Developing the process for individuals with severe disabilities. Techniques, 1 (6), 463-472.

McLeod, B. (1985, March). The last minority. Psychology Today.
O'Neill and Associates (1984). Competitive employment summary update of placements made from adult day programs. Seattle: State of Washington, Office of Developmental Disabilities.

Paine, S. C., Bellamy, G. T., \& Wilcox, B. L. (1984). Human services that work: From innovation to standard practice. Baltimore: Paul $\mathrm{H}$. Brookes.

Pancsofar, E. (1985). Community-based living facilities. In P. Wehman, A. Renzaglia, \& P. Bates (Eds.), Functional living skills for moderately and severely handicapped individuals (pp. 22-44). Austin, TX: Pro-Ed.

Revell, G., Wehman, P., \& Arnold, S. (1984). Supported work model of competitive employment for persons with mental retardation: Implications of rehabilitative service. Journal of Rehabilitation, 50(4), 33-38.

Rhodes, L., \& Valenta, L. (1985). Industry-based supported employment: An enclave approach. Journal of the Association for the Severely Handicapped, 10, 12-20.

Rusch, F. R. (Ed.). (in press). Competitive employment: Service delivery models, methods, and issues. Baltimore: Paul H. Brookes.

Rusch, F. R., \& Chadsey-Rusch, J. (1985). Employment for persons with severe handicaps: Curriculum development and coordination of services. Focus on Exceptional Children, 17(9), 1-8.

Rusch, F. R., \& Mithaug, D. (1980). Vocational training of mentally retarded adults. Champaign, IL: Research Press.

Savage, V. T., Novak, A. R., \& Heal, L. W. (1980). Generic services for developmentally disabled citizens. In A. R. Novak \& L. W. Heal (Eds.), Integration of developmentally disabled individuals into the community (pp. 75-90). Baltimore: Paul H. Brookes.

Scheerenberger, R. C. (1974). A model for deinstitutionalization. Mental Retardation, 12(6), 3-7.

Scheerenberger, R. C. (1976). Deinstitutionalization and institutional reform. Springfield, IL: Charles C Thomas.

Thompson, M. M. (1977). Housing for the handicapped and disabled: A guide for local action. Washington, DC: National Association of Housing and Redevelopment Officials.

Wehman, P. (1981). Competitive employment: New horizons for the severely disabled. Baltimore: Paul $\mathrm{H}$. Brookes.

Wehman, P., Hill, M., Goodall, P., Cleveland, P., Brookes, V., \& Pentecost, J. (1982). Job placement and follow-up of moderately and severely handicapped individuals after three years. Journal of the Association for the Severely Handicapped, 7, 5-16.

Wehman, P., Hill, M., Hill, J., Brookes, V., Pendleton, P. \& Britt, C. (in press). Competitive employment for persons with mental retardation: A follow-up six years later. Mental Retardation.

Wehman, P., \& Kregel, J. (1985). A supported work approach to competitive employment of individuals with moderate and severe handicaps. Journal of the Association for Severely Handicapped, 10, 3-11.

Wehman, P., Kregel, J., \& Barcus, M. (in press). School to work: A vocational transition model for handicapped youth. Exceptional Children.

Wehman, P., \& Melia, R. (1985). The job coach: Function in transitional and supported employment. American Rehabilitation, 11(2), 4-7.

Wehman, P., \& Moon, S. (1985). Critical values in employment programs for persons with developmental disabilities. In P. Wehman \& J. Hill (Eds.), Competitive employment for persons with mental retardation: From research to practice. Richmond: Virginia Commonwealth University.

Wehman, P., Renzaglia, A., \& Bates, P. (1985). Functional living skills for moderately and severely handicapped individuals. Austin, TX: Pro-Ed.

Wilcox, B., \& Bellamy, G. T. (1982). Design of high school programs for severely handicapped students. Baltimore: Paul H. Brookes.

Will, M. (1984). OSERS programming for the transition of youth with disabilities: Bridges from school to working life. Washington, DC: Office of Special Education \& Rehabilitative Services, U.S. Dept. of Education.

Willer, B., Intagliata, J., \& Wicks, N. (1981). Return of retarded adults to natural families: Issues and results. In R. H. Bruininks, C. E. Meyers, B. B. Sigford, \& K. C. Lakin (Eds.), Deinstitutionalization and community adjustment of mentally retarded people (pp. 207-216). Washington, DC: American Association on Mental Deficiency.

Zetlin, A., \& Turner, R. (1985). Transition from adolescence to adulthood: Perspectives of mentally retarded individuals and their families. American Journal on Mental Deficiency, 89(6), 570-579. 